VULVOVAGINITIS IN CHILDREN : AN ACCOUNT OF ITS ETIOLOGY, SYMPTOMATOLOGY AND MANAGEMENT, WITH A SUMMARY OF SIXTY-THREE CASES OCCURRING IN SOUTH AFRICA

By A. REITH FRASER, M.D. (Aberd.). From the Department of Venereal Diseases, University of Cape Town, Union of South Africa.

WHEN one regards the importance of vulvovaginitis in children as a disabling and distressing condition, one is struck by the remarkably scant and incomplete attention which it has received in literature. In view of its prevalence and the astonishing lack of success in its treatment this neglect is peculiarly unmerited.

No greater calamity can befall a household than the wholesale infection of the female children with the gonococcus. That such accidents occur too frequently is clear to most workers in dispensary services, yet no generally accepted method of management has been evolved. It is true that epidemics occur most frequently in institutions for female children, but widespread infection occurs in the homes of families who are ignorant of its manner of introduction, who are astounded at the medical man's inability to deal with the disease, and who eventually are ready to spend their resources to the uttermost farthing to get rid of the scourge which threatens to blight the youthful lives of their offspring.

Yet the medical profession as a whole has failed to treat the condition of specific vulvovaginitis as a serious menace to the health of our children. Indeed, it is a disease which has been neglected by the health administrator, the pediatrician, the gynæcologist, the venereologist, and the general practitioner. It may be that the disease has a higher incidence in South Africa than in other countries, for it has fallen to one's lot to see an astonishing number of cases. Nevertheless, workers in other countries are gradually awakening the interest of the medical profession 


\section{VULVOVAGINITIS IN CHILDREN}

to the prevalence of this condition-a prevalence which previously has not been fully appreciated. Kidd and Simpson, ${ }^{56}$ working in the London Hospital, state that their " Experience at the clinic has opened their eyes to the prevalence of gonorrhœa in female children."

\section{INCIDENCE}

Suchard (I877) appears to have reported the first recognised epidemic of vulvovaginitis, which occurred through the medium of a swimming bath. ${ }^{1}$

Atkinson (I878) ${ }^{2}$ recorded a hospital epidemic which lasted for thirteen months.

Pott (I883) ${ }^{3}$ appreciated the infective nature of the disease, observing 86 cases of infection among 3,92I female children.

Skutsch (I89I) ${ }^{4}$ also described a similar epidemic when 236 children became infected in a public swimming bath. A point of interest was that a number of boys who also used the bath escaped contamination.

Koplik (I893) demonstrated the gonococcus in I7 cases of vulvovaginitis, failing to do so in the remaining 7 cases of his series. ${ }^{5}$

De Minine (I895) ${ }^{6}$ discusses the incidence of the disease among coloured children resulting from direct sexual approach.

Robertson (I899) ${ }^{7}$ was able to demonstrate the gonococcus in $4 \mathrm{I}$ out of 54 cases.

Romniceanu and Robin (IgOI) ${ }^{8}$ found the gonococcus present in I30 of their series of 150 cases.

Kimball (I903) records 70 cases due to the gonococcus among 600 children admitted to the public ward of the Babies' Hospital, New York. ${ }^{9}$

Veil and Bayon (I904) describe an epidemic due to contagion by a thermometer, ${ }^{10}$ and Welt-Kakels (I904) recorded a series of I9o cases in the Mount Sinai Hospital Dispensary. ${ }^{11}$ Baer's epidemic occurred in the same year. ${ }^{12}$ Holt ${ }^{13}$ observed four epidemics between 1899 and I904.

Cotton ${ }^{14}$ reports an epidemic in I905, Plomley ${ }^{15}$ in I906, and Hurdon ${ }^{16}$ in I907.

Pollack (I909) ${ }^{17}$ worked out the yearly incidence in Baltimore, and found an average of from 800 to $I, 000$ young girls infected. 


\section{BRITISH JOURNAL OF VENEREAL DISEASES}

Morrow and Bridgman (IgI2) state that 55 per cent. of the female children admitted to the State Training School for Girls, Geneva, Illinois, were found to be suffering from gonococcal contamination. ${ }^{18}$

Watson (IgI4) ${ }^{19}$ finds that 2 to I2 per cent. of the female children applying for surgical or medical attention in Glasgow show the presence of gonococci in vaginal discharges.

Kidd and Simpson (I924) ${ }^{\mathbf{5 6}}$ found that no less than fifty infected children were met with in 650 cases; that is to say, at their clinic I case in I3 was a child, or roughly 8 per cent.

Vulvovaginitis is frequently rampant in places where female children congregate together, such as schools, crowded tenements, and public playgrounds. In Europe its incidence is highest in the miserable, squalid, overcrowded dwellings of the poor. It is rare, however, in children of the well-to-do classes. This is particularly true of Europe, but to a less extent of America, where the negro complicates matters. In South Africa, on the other hand, where the population is a heterogeneous one, with the white man in the minority, the prevalence of the disease is remarkable, even in the homes of well-to-do families. This is entirely due to the coloured man, especially in the coastal towns. The coloured half-breed and native nursemaids appear to be responsible for the vast amount of such sporadic infection, but the lavatory seat undoubtedly adds its quota to the high incidence of this malady among the children of well-to-do families in certain parts of South Africa.

\section{MODEs OF INFECTION}

To determine the real source of infection in female children presents a problem of extreme difficulty which is often impossible of solution. Norris ${ }^{20}$ indicates the difficulty of the problem by suggesting that the disease may be propagated "By accidental infection, by the infectionist, by the sadist, by precocious sexual intercourse, and in rare instances by the passage of the child through an infected maternal birth canal."

Naturally the manner of transmission varies with the age of the child. Most authorities believe that accidental contamination is the most common. In dispensary 


\section{VULVOVAGINITIS IN CHILDREN}

districts Kidd and Simpson, ${ }^{\mathbf{1}}$ Lees, ${ }^{21}$ Norris, ${ }^{20}$ and others, believe that infection is carried from the adult parent, frequently as a result of parents and children sleeping together. Articles such as towels, sponges, toilet utensils, napkins, baths, and lavatory seats are all held responsible. Taussig ${ }^{22}$ bélieves that the most frequent source of infection is from child to child, and that the most common manner of its transmission is through the school lavatory. In South Africa two methods of transmission appear responsible for 99 per cent. of all cases. The one is the hand of the infected, coloured nurse girl, and the other is the lavatory seat. How far the former indicates amorous dallying with the child's genitalia is impossible to estimate. The fact that gonorrhœa in little boys is relatively common seems to add weight to the hypothesis that such manœuvring is probably a very important factor. Kidd and Simpson ${ }^{\mathbf{5 6}}$ believe that sporadic cases are " probably due to tricks played on the sexual organs by amorous governesses or servants."

Norris, ${ }^{20}$ Watson, ${ }^{19}$ Lees, ${ }^{21}$ and many others draw attention to infection resulting from " the horrible superstition surviving amongst the ignorant and vicious that contact with an immature vulva will ensure cure of a urethritis."

In America this belief, according to Norris, is widespread, especially among ignorant foreigners, and in London the tradition is deeply rooted among the lower classes. ${ }^{56}$ Fortunately the coloured man in South Africa has not yet learned this appalling doctrine, and, therefore, no cases of such infection have been met with. Criminal assault occasionally accounts for transmission of the disease, but unless there is some definite evidence pointing towards such an issue, it need not enter our calculations. Cases illustrating such means of contamination are reported in Pollack's series, ${ }^{17}$ by Seippel, ${ }^{23}$ while Pott ${ }^{3}$ found definite evidence that the parents of a large percentage of his cases were infected with genital discharges of sorts. Kidd and Simpson ${ }^{\mathbf{5 6}}$ found two cases in a series of 50 where there was a history of rape, and the writer has seen only one case in his South African series. Masturbation has also been responsible for epidemics in institutions.

Morton ${ }^{24}$ called. attention to the serious menace of the lavatory seat, and Taussig ${ }^{22}$ emphasised similar views in 


\section{BRITISH JOURNAL OF VENEREAL DISEASES}

I9I4. These authors advocate a lavatory seat with the central portion of the front removed for use in institutions and public toilets. Sanitary privy seat covers have been introduced with a similar object, ${ }^{25}$ but simple paper covering of the seat is not wholly satisfactory. ${ }^{19}$ There seems to be considerable evidence that the public lavatory, particularly in schools and similar institutions, is rightly entitled to a very large share of the responsibility of spreading infection. The gonococcus is supposed to be an exceedingly delicate organism outside the human body, and desiccation will kill it in a very short time. Such absorbent articles as clothing, bed linen, and towels, infected with discharge, in most cases will be sufficiently dry in about an hour to cease to be a serious source of contamination. On the lavatory seat, however, moisture is abundant, and the organism is secure for some considerable time in its pabulum of mucus. Under circumstances such as these the small child who has to manœuvre the difficulties of a high seat will frequently succeed in smearing her genitalia with infective material.

In this connection it is interesting to note the work of Engering, ${ }^{55}$ which goes to show that the viability of the gonococcus outside the human body is considerably greater than has generally been supposed. In spite of being unable to reproduce natural conditions faithfully, he was able to show that, depending on the particular strain of organism, gonococci lived in sterile tap water at a temperature of $22^{\circ} \mathrm{C}$. from three to ten hours. In the surface water of a swimming-bath the organism kept alive seven and a half to ten hours, and in the deep water eight to fourteen hours. On linen kept moist the bacterium survived for four hours, but if the linen was kept dry the germ died in half to one hour. Pure cultures of gonococci lived on wet sponges for twenty-four hours. From this investigation it will be seen that female children run much greater risks than has ever been dreamt of.

The clinical thermometer has been held responsible for the spread of the disease in institutions. ${ }^{10}$ Reference has been made to epidemics caused by public baths, ${ }^{2,4}$ and Hamilton, ${ }^{29}$ Stein, ${ }^{30}$ Engering, ${ }^{55}$ and others subscribe to this idea. Bendig ${ }^{31}$ described how contagion took place as a result of bathing two girls simultaneously in the same bath water. In the light of Engering's statistics such 


\section{VULVOVAGINITIS IN CHILDREN}

contamination is by no means surprising. Macartney and Fraser ${ }^{51}$ describe how children in poor quarters sit around with no protection whatever for the perineum, and Norris ${ }^{20}$ relates similar circumstances where children sit on doorsteps and rugs that have previously been soiled by a filthy and perhaps drunken parent.

In endeavouring to trace the source of contagion in sporadic cases cropping up in well-kept homes, inquiries should be directed to the urogenital state of all persons living in the same house, and also to that of occasional servants, cleaners, houseboys and workmen who may have come in contact with the child or may have occasion to use the household lavatory. We have emphasised the importance of the coloured nurse girl in South Africa. Kidd and Simpson ${ }^{\mathbf{5 6}}$ at their clinic have had whole families up for investigation, " as it is useless treating a single child in a family without investigating all the other members." Otherwise reinfection occurs again and again. They find that usually the father or the mother and two or three of the children are infected, while at other times parents are free and brothers or sisters have it. In some cases they have traced the origin to children of one family , playing with infected children of another family. Taussig ${ }^{22}$ does not consider the mother a potent source of danger, and Rachford ${ }^{26}$ exonerates the hand of the adult nurse. He draws attention to the interesting fact that adult female nurses in charge of these cases never become infected themselves.

Vulvovaginitis neonatorum is recognised as a clinical entity, but is exceedingly rare, although some workers have stated that it occurs more often than is supposed. Lees ${ }^{21}$ recognises the condition, but regards its low incidence as being due to the fact that the parts are usually well washed and cleansed immediately after birth. Morton ${ }^{24}$ believes that breech presentations increase the possibility of such infection. Kidd and Simpson ${ }^{\mathbf{5 6}}$ are sceptical of such an infection occurring, and have found no evidence in support of the idea. Cases, however, have been recorded by Epstein ${ }^{27}$ (I89I), Woods ${ }^{28}$ (I903), and some others.

\section{ETIOLOGY}

All workers are agreed that the gonococcus is the most frequent etiological factor in the production of vulvo- 


\section{BRITISH JOURNAL OF VENEREAL DISEASES}

vaginitis in children. Indeed, Taussig ${ }^{22}$ suggests that for practical purposes vulvovaginitis may be termed gonorrhœa. Guiteras declares that the gonococcus is the agent in 75 per cent. of all cases, and that saprophytic organisms are responsible for the remainder. $\mathrm{Abt}^{\mathbf{3 2}}$ found $7 \mathrm{o}$ to $8 \mathrm{o}$ per cent. of cases gonococcal in origin, while Barkenheim estimated the gonococcal percentage as 75. Dukelski's figure ${ }^{34}$ was even higher, and he gives it at 80 per cent., while Plonley ${ }^{15}$ worked out a percentage of 85.7 in his series. Spaulding ${ }^{35}$ found 56 cases of gonococcal infection in a series of 83. Other examples were associated with acute infectious diarrhœea, pneumonia and trauma. She noted a staphylococcal and streptococcal variety following chickenpox and measles. Wollstein ${ }^{36}$ found no difficulty in getting pure cultures of the gonococcus, and Abraham, ${ }^{\mathbf{3 7}}$ Van Gieson, ${ }^{\mathbf{3 8}}$ Irons and Nicoll, ${ }^{\mathbf{3 9}}$ Pearce, ${ }^{\mathbf{4 0}}$ Norris, ${ }^{20}$ Watson, ${ }^{19}$ Bayly, ${ }^{41}$ and many others, have had similar experience. Norris and Mickelberg ${ }^{\mathbf{4 2}}$ emphasise the difficulty of demonstrating the gonococcus in chronic cases where its morphology has become altered, and where errors are easily made with Gram's stain. This is a very real difficulty, and should always be borne in mind where a stone-wall diagnosis cannot be made. Clinical findings must then be brought in to decide one way or another. Rubin ${ }^{\mathbf{4 3}}$ similarly deprecates too much reliance on staining methods in diagnosis, placing his faith rather in cultural and serologic tests. Where staining methods are inconclusive, however, cultural methods are invariably still more so. In such cases we believe, with Norris and Mickelberg, ${ }^{42}$ that clinical evidence should pull its full weight in the diagnostic procedure.

Considerable work has been done in the investigation of the organism responsible for vulvovaginitis. Van Gieson ${ }^{\mathbf{3 8}}$ contributed a paper in IgIo. Kolmer and Brown, ${ }^{44}$ G. G. Smith, ${ }^{45}$ Irons and Nicoll, ${ }^{39}$ and others found a positive complement fixation reaction to the gonococcus in many cases. The suggestion that the type of gonococcus responsible for vulvovaginitis belongs to a special group different from that found in the adult has been put forward by such workers as Pearce ${ }^{40}$ and Cole and Lloyd, ${ }^{46}$ and denied by others. ${ }^{47}$ R. M. Smith ${ }^{48}$ believes there is a definite group of vulvovaginitis of variable nongonorrhoal bacterial origin, and reports two cases due to Micrococcus catarrhalis. Fischer ${ }^{49}$ describes simple catar- 


\section{VULVOVAGINITIS IN CHII.DREN}

rhal vaginitis due to a diplococcus other than Neisser's bacterium.

Anderson, Schultz and Stein ${ }^{\mathbf{4}}$ in their series found only 35.7 per cent. due to the gonococcus and 64.3 per cent. to other organisms. They confess, however, that it is possible that many of their non-specific cases may have been chronic gonococcal conditions where it was impossible to demonstrate this organism. In all chronic gonococcal conditions the specific bacterium is notoriously difficult of demonstration, and this consideration must influence the importance we otherwise may attach to the figures supplied by these workers. They state dogmatically, however, that "the smear method as a diagnostic procedure is preferable to the cultural method in office and dispensary work. The gonococcus was not cultivated from any case in which it was not detected in smears. The failure of the cultural method to establish a specific diagnosis in cases negative on repeated direct examination gives to the cultural method no advantage which compensates for its greater technical difficulty." The nonspecific organisms demonstrated were streptococci of intestinal origin, staphylococci, colon bacilli and Grampositive bacilli. The first-named, introduced doubtless by fæcal contamination of the vulva, was the most important, and the others were probably secondary invaders or harmless symbionts. These workers consider uncleanliness and local irritation to be important and probably primary factors in non-specific cases, the condition thus established being maintained by bacterial localisation. The pneumococcus was found in only one instance.

Warden $\mathbf{5 0}$ states that the staphylococcus urethræ is often mistaken for the gonococcus in smears, and that cultures alone can differentiate them. Nabarro ${ }^{51}$ reminds us that in the same way the pneumococcus is frequently taken for the so-called enterococcus.

That other organisms may produce a vulvovaginitis there is no doubt. Many, however, are secondary to an original gonococcal infection. The symbiosis of a staphylococcus and a diphtheroid bacillus should always stimulate further search for the diplococcus of Neisser. In I896 Veillon and Halle ${ }^{52}$ described vulvovaginitis due to B. pseudo-diphtherice, streptococci, staphylococci and occasionally $B$. coli. Sherber, ${ }^{53}$ in I9Io, found clinical cases 


\section{BRITISH JOURNAL OF VENEREAL DISEASES}

showing the presence of vibrios and spirochætes. Chapple ${ }^{\mathbf{5 4}}$ described a transient vulvovaginitis due to the pneumococcus, while other workers have described $B$. diphtheria and Vincent's organisms attacking this region. Various pyogenic bacteria may set up a vulvitis and vaginitis in association with the irritation of thread-worms in the rectum.

Vaginitis associated with peritonitis of pneumococcal origin is a recognised clinical condition of very grave import. Waugh, ${ }^{51}$ discussing pneumococcal peritonitis, reported the case of a female child aged fourteen months, who, after six days' illness, showed the left side of the abdomen and pelvis as high as the iliac crest to be full of fluid. The pneumococcus was present in the vaginal discharge, and he thought the infection had spread from the left tube. Nabarro ${ }^{51}$ recorded a case diagnosed as pneumococcal peritonitis in which organisms recovered from the vagina were $B$. coli and streptococcus. $\mathrm{He}$ believed that many cases diagnosed as pneumococcal were really due to other organisms such as the so-called enterococcus. Macartney and Fraser ${ }^{51}$ are quoted as suggesting that the immature female vagina offered a peculiarly favourable hunting ground for the pneumococcus, which eventually makes its way into the abdomen viâ the genital tract and tubes. These authors pointed out that the pneumococcus was recoverable from the vagina in every case, that the first symptoms were those of subumbilical peritonitis and that at laparotomy, in early cases, pus was found in the pelvis only. They had reproduced the disease in a female monkey by introducing the pneumococcus into the vagina after rendering this passage alkaline.

Dirt and filth frequently produce vulvovaginitis in the neglected children of the poor. Impetigo of the genitals, superficial ulcers, pediculi, scabies, staphylococcal and streptococcal skin lesions and eczemas may all lead to the evolution of a non-specific dirt-vulvovaginitis.

Other causes of vaginal discharges in young children are attempts at coitus, the lacerations and excoriations of attempted rape, and tuberculous ulceration. The mucoid excess of girls approaching puberty is frequently misinterpreted as pathological, and such cases appear for examination at every clinic.

The anatomy of the lower genital tract in the adolescent

$$
276
$$




\section{VULVOVAGINITIS IN CHILDREN}

female has an important bearing. The genitalia at this stage of development are unprotected. They are smooth, hairless and everted, and the labia are small, immature, and seldom in complete apposition. With the advent of puberty the labia develop and receive adequate protection from the growth of hair. After this stage vulvovaginitis in cleanly women becomes a pathologic rarity. Indeed, the mature vulva is not a suitable hunting ground for the gonococcus. In the adult vulvitis usually occurs secondarily to a urethritis, endocervicitis, or implication of Bartholin's glands. Unclean habits, low mentality, and a previous infection enabling the gonococcus to penetrate, are conditions necessary for such an infection, and these occur only in the feeble-minded and the unclean. Other important factors are the absence of menstruation and the fact that the vaginal flora, and particularly the bacillus of Döderlein, does not make its appearance until the approach of puberty.

\section{Clinical Picture}

Vulvitis is the main symptom of the disease. The onset is acute and is ushered in by a sensation of itching or warm irritation at the vulvar orifice. Redness, heat and swelling are apparent. The skin in this region is exceedingly delicate and the gonococcus is able to penetrate deeply without difficulty. The infrequency of vaginitis in the adult and its great prevalence in children are most striking, and the behaviour of the gonococcus in each case varies according to the resistance or receptivity of the vaginal lining membrane.

The hymen offers no obstruction to upward spread, and the vaginal mucosa, in contrast to that in the adult, is peculiarly susceptible to attack. The lower third of the vagina bears the brunt, and as the case advances inflammation may spread to the fornices or to the vaginal surface of the os. The endocervix, however, is seldom affected, for the canal is rudimentary and the os is closed. Upward spread to the endocervix occurs occasionally, however, both in gonococcal, pneumococcal and probably other types of vulvovaginitis as well.

The whole mucosa becomes intensely inflamed and is bathed in thick, creamy pus, which overflows and oozes from the vestibule to the exterior. This thick, 


\section{BRITISH JOURNAL OF VENEREAL DISEASES}

yellowish discharge is seen covering the labia. The vestibule and hymen are red, inflamed and œdematous, while the labia are swollen, tender, and glued together. Excoriation of the vulva accompanies a surrounding intertrigo. Suppurating scratches, encrustations, bleeding surfaces of denuded skin areas, superficial ulceration, and occasionally condylomata acuminata may be seen on the labia and surrounding skin in neglected cases.

The discharge is at first thin and ichorous, but later becomes thick, yellow or greenish-yellow, profuse and offensive. It tends to collect behind the hymen, only the overflow appearing at the vulva. Its flow, therefore, can often be greatly augmented by expulsive efforts on the part of the patient. As time goes on the discharge becomes mucinoid, thin, and very scanty. In chronic cases and frequently in early cases-vulvovaginitis chronique d'emblée - the mucous membrane appears healthy and non-inflamed, the secretion is mucinous, epithelial and non-purulent, but gonococci can be recovered in culture from secretions which are negative in smears.

In the majority of cases there is no pronounced discomfort after the first few days There may be some vesical irritability and frequency of urination, the act being accompanied by sensations of burning and stinging. As a result, a condition of voluntary retention may follow. The child complains of local itching and of feeling chafed. On the other hand, the child may not complain, and there are no local symptoms of any kind. The disease in these cases is frequently discovered by the finding of a tell-tale stain on the night clothes. In acute cases there may be severe pain between the legs which is increased by walking, and later on purulent excoriations, heat and intense itching as a result of scratching, uncleanliness and neglect.

Acute inflammatory symptoms usually disappear within twenty-one days, when the discharge becomes scanty, thin and serous in character. At this time symptoms are exceedingly mild and are frequently overlooked. The disease runs a long and tedious course. Gonococci persist with relentless tenacity. Treatment is often unsatisfactory and well-nigh heartbreaking, and is tedious alike for child, nurse and physician. The rectum shares involvement in the vast majority of cases, and as a focus of superinfection is ideally situated. Indeed, it is so 


\section{VULVOVAGINITIS IN CHILDREN}

rare for the rectum to escape that rectal implication should be regarded as a phase of the disease rather than a complication. Severe constitutional symptoms invariably indicate the onset of metastatic or direct extension complications, but these, fortunately, are very rare indeed. The child seldom suffers in general health, but she finds treatment, isolation, continuous nursing and supervision trying and irksome. In older children the physician's difficulties are increased tenfold. There is ever present the great danger that their minds may become focussed on their sexual apparatus with a morbid curiosity which, in precocious children, may perfetuate much moral damage. For this reason alone it is desirable that as much of the treatment should be carried out by the nurse and as little by the physician as possible.

The disease tends to run a long and chronic course characterised by frequent relapse. Long gonococcus-free intervals are followed by spells of organismal activity accompanied by pus production. In short, the grave character of this disease lies in its long duration and its rebelliousness against treatment, together with its undoubted potentialities for permanently damaging very important structures.

According to Kimball, ${ }^{9}$ children under one year of age are more amenable to treatment than older children.

Pontoppidan ${ }^{57}$ believes that the disease never persists into adult life. He investigated a large series of cases and collected statistics. Relapse was not uncommon, but re-examination after long periods showed all but two clinically cured. Bock ${ }^{\mathbf{5 8}}$ expresses a similar opinion. Contrary to the general opinion, however, Von Butzke ${ }^{\mathbf{5 9}}$ considers relapse uncommon.

Perrin ${ }^{60}$ obtains a cure in two to three weeks. Barnett ${ }^{61}$ reported a case which persisted for six years, while the average duration of cases under treatment was eight and a half months: Skutsch ${ }^{4}$ found gonococci persisting in a considerable percentage of his patients after twelve weeks' treatment, while Norris ${ }^{62}$ was able to secure complete cure of his cases within the same period. Valentin ${ }^{63}$ found relapse frequent, even after four to eight weeks of energetic treatment. In 6I cases where relapses occurred the gonococcus was found to persist in the rectum. Epstein ${ }^{27}$ has found cases persisting from infancy until the child had reached the age of ten. The difficulty in 


\section{BRITISH JOURNAL OF VENEREAL DISEASES}

securing rapid cure, the exasperating tendency to relapse after clinical and often bacteriological cure has seemed to be attained, and the appalling inefficiency of many treatment methods have been illustrated in contributions by Hamilton, ${ }^{29} \mathrm{H}$. Hamilton, ${ }^{64}$ Spaulding, ${ }^{35}$ Cotton, ${ }^{14}$ Doleris, ${ }^{65}$ Rubin and Leopold, ${ }^{66}$ Luys, ${ }^{67}$ Bruschke, ${ }^{68}$ Reith Fraser, ${ }^{69}$ and many others. Kidd and Simpson ${ }^{56}$ tell us that " no disease can more severely tax the patience of doctor or nurse, yet with perseverance there are few cases that will not finally yield to treatment based on experience." They were able to cure their patients on an average in four months, but where any case persisted beyond this period they naïvely consoled themselves by "suspecting reinfection."

Whether final clinical cure marks the termination of local physical damage is by no means certain. It is true that the majority of cases tend to spontaneous cure with the advent of puberty, whether treatment is undertaken or not. On the other hand, there is much reason to believe that permanent anatomical damage is by no means infrequent. Norris ${ }^{20}$ states that adhesions and atresia may occur in ill-treated cases, and quotes Findley, ${ }^{70}$ who declares that certain so-called congenital anomalies, such as imperforate hymen, adhesions, and malformation of the uterus and adnexa, may be ascribed to gonorrhœa acquired in utero.

Welt-Kakels (I904) ${ }^{72}$ quotes Sanger and Currier as being responsible for the opinion that some of the pelvic inflammations seen in young virgins may be directly the result of a persisting vulvovaginitis contracted in infancy. Further, the latter worker suggested that undeveloped uteri with resulting dysmenorrhœa and sterility were frequently due to infantile gonorrhœa. Watson 20 also reminds lis that: "As long as the gonococcus remains in the genital tract the patient is liable to an attack of salpingitis with its sequelæ of adhesions and, later, interference with the menstrual function." Dealing with prognosis, Martin, Thomas and Whitehead ${ }^{\mathbf{7 6}}$ make this statement: "The prognosis is good. None the less, cases of peritonitis and death have been reported, and on the basis of apparently clear clinical records it has been shown that this inflammation in infancy may occasion imperfect development of the genitalia, sterility, and chronic invalidism in later life." 


\section{VULVOVAGINITIS IN CHILDREN}

Wessels ${ }^{71}$ goes further, and suggests that chronic inflammations in childhood are responsible for many so-called congenital anomalies, and that it is probable that gonorrhoea is the most important etiological factor. He produces statistics of many cases where such anomalies are clearly inflammatory in origin and etiology, but where it is impossible to state what bacterium was originally responsible. This point must remain undecided until statistical reports are furnished from follow-up cases by the gynæcologist.

\section{DiAgNosis}

The point at issue with regard to diagnosis is whether failure to find the gonococcus is to be regarded as conclusive or not. There is little doubt that the majority of cases are gonococcal in origin, but after months have elapsed it is exceedingly difficult to find the gonococcus. Except for the very small percentage of cases which are pneumococcal in etiology, it is one's opinion that the remainder are due directly or indirectly to primary gonococcal infection. Cases which show only the presence of staphylococci, streptococci (mostly of the intestinal type), diphtheroid bacilli and $B$. coli, in the first place were probably gonococcal. It is true that several types of Gram-negative diplococci have been found which culturally were not gonococci. What these organisms are is not clear, but it is highly probable that they are merely involuted gonococci. It is further probable that, were the very large percentage of non-specific cases seen early enough, the gonococcus could be recovered in practically Ioo per cent. of cases.

Diagnosis turns on the demonstration of the gonococcus in the discharge. In acute cases this is never difficult, but in chronic cases it is difficult and often impossible. Indeed, so difficult is this of accomplishment that it has led numerous workers to doubt the culpability of the gonococcus and to describe conditions due entirely to other organisms-organisms which in our opinion are merely secondary symbionts. The practitioner should never be satisfied with a single negative laboratory report. Where nothing is demonstrated but an association of a diphtheroid bacillus and a staphylococcus, an original gonococcal infection should invariably be suspected. Many times a culture from the rectum will succeed in $28 \mathrm{I}$ 


\section{BRITISH JOURNAL OF VENEREAL DISEASES}

demonstrating Neisser's bacterium when vulval and urèthral smears and cultures have proved negative.

\section{Complications}

In actual practice complications are extremely rare. By far the most common is rectal implication, but this should be considered rather as a symptom of the disease. As such it occurs in practically Ioo per cent. of cases. It is astonishing, in view of one's experience in South Africa, to learn that Kidd and Simpson ${ }^{56}$ saw no instance of proctitis in their series of 50 cases. Nor does Watson ${ }^{\mathbf{1 9}}$ mention rectal implication as a complication. Kaumheimer ${ }^{73}$ believed proctitis to be extremely common and in most cases symptomless. This is undoubtedly so. In the majority of cases there are no obvious rectal symptoms, but gonococci can be recovered from the rectal mucosa by culture. Valentin, ${ }^{63}$ in her series of $\mathrm{I} 6 \mathrm{I}$ cases, demonstrated the gonococcus persisting in the rectum in the 6 I cases in whom recurrences occurred.

Urethritis is stated to occur in Io per cent. of cases by Kidd and Simpson, ${ }^{56}$ while Norris;, ${ }^{20}$ Watson, ${ }^{19}$ and Martin, Thomas and Moorhead, ${ }^{76}$ describe it as part of the clinical picture. Abraham ${ }^{37}$ also considers it an inevitable implication, and believes that relapse is due to insufficient attention being directed to the urethra, vaginal vault or anus, from any of which sites re-inoculation may occur. There seems no reason to expect that the urethral orifice should escape infection, for its situation is such that contamination is inevitable. How far the inflammation spreads along the urethra is difficult to determine, and only when cystitis supervenes is a complete urethritis proved. Cystitis, however, is of rare occurrence, Bruschke ${ }^{68}$ reporting only one case in a series of 50.

Involvement of Bartholin's glands occurs occasionally, and does not differ clinically from a similar condition in the adult. Watson ${ }^{19}$ believes that the condition is by no means uncommon, and occurs just as frequently as in the adult. McDonagh, ${ }^{75}$ on the other hand, states that Bartholinitis does not complicate vulvovaginitis.

Inguinal adenopathy is frequently present, but seldom goes on to suppuration.

Venereal warts in neglected cases may attain considerable size and number. 


\section{VULVOVAGINITIS IN CHIIDREN}

Although peritonitis following gonococcal vulvovaginitis has been described by many authors, its actual occurrence is very rare indeed. In untreated cases it may be met with occasionally, but where efficient vaccine therapy has been employed its incidence has receded to vanishing point. There is little doubt that upward spread is extremely infrequent, doubtless due to the rudimentary canal and the absence of menstruation. Peritonitis, then, is probably hæmic in transmission, much more commonly than in the adult.

Holt ${ }^{13}$ found no instance of peritonitis in his series of 273 cases, and Kidd and Simpson ${ }^{\mathbf{5 6}}$ state that this complication is almost unknown. Norris, ${ }^{20}$ however, describes its incidence as not infrequent, and Watson, ${ }^{19}$ Lees, ${ }^{21}$ and others consider its possibility as a risk which must be considered seriously. Cases have been recorded by Jung, ${ }^{77}$ Carpenter, ${ }^{78}$ Bidwell, ${ }^{79}$ Galvagno, ${ }^{80}$ Dowd, ${ }^{74}$ Koplik, ${ }^{5}$ Baer, ${ }^{12}$ Variot and Sebilleau, ${ }^{81}$ Northrup, ${ }^{82}$ and many others. Only one instance occurred in the writer's series.

Arthritis occurs but rarely. Kidd and Simpson ${ }^{56}$ met with two cases, Koplik records two cases, ${ }^{\mathbf{5}}$ and Pollack ${ }^{17}$ three cases.

Ophthalmia is said to occur frequently as a result of hand contamination, but the risk appears to be greatly exaggerated. Hamilton ${ }^{64}$ met with four examples in his series of 344 cases, the ages of which ranged from three weeks to twelve and a half years. While vulvovaginitis is exceedingly common, gonorrhœal ophthalmia in growing children is correspondingly rare.

The sequelæ of vulvovaginitis are, in the opinion of the writer, more important clinically and prognostically than complications. These constitute two groups : (I) the evolution of the carrier, and (2) the acomplishment of anatomical damage. In common with other workers, we have found it by no means rare for cases to settle down clinically with inflammation gone and mucous surfaces apparently healthy, and yet the gonococcus is present on the vulvar walls. These cases constitute the true carrier, and the problem of exterminating the gonococcus under such circumstances has not yet been solved. Whether these carriers clear up eventually or not has not been proved, but it is probable that they are responsible for many of the epidemics which so frequently occur in institutions. 


\section{BRITISH JOURNAL OF VENEREAL DISEASES}

The possibility of permanent anatomical damage with the production of such conditions as pinhole os, imperforate hymen, malformations of uterus and adnexa, and so on, has already been referred to. Should these conditions be the result of vulvovaginitis in infancy, then the chief dangers undoubtedly lie in this aspect of the disease.

\section{Examination of the Patient}

Examination of these patients is always difficult. The first essential is to win the child's confidence. In older children who are approaching puberty, and particularly where one is seeing the child only rarely, as, for example, in a consulting capacity, examination with the aid of general anæsthesia is often advisable. The child may be placed in an elevated position, or, if preferred, the kneechest posture may be utilised. The vulva is cleansed, and smears are taken from the vulva, the urethral orifice, and the rectum, and culture tubes inoculated. A Kelly's speculum of suitable size, or the short straight tube of a male urethroscope of the Luys' pattern, is then passed, without rupturing the hymen. The cervix is enticed into the field and smears are made. The vaginal vault is also examined in this manner. Erosions, reddened and infiltrated areas, œdematous patches and inflamed crypts and crevices are noted, and topical applications may be made at the time of examination.

Special instruments have been devised for examining the immature female vagina. It has been noted that even in very small children the vagina is quite capacious behind the hymen, and this has led to the exploitation of internally-illuminated expanding specula. Such an instrument has been described by Sheaff. ${ }^{83}$ Watson's suggestion ${ }^{19}$ to cut the distal end of the ordinary urethroscope tube obliquely like the Fergusson speculum is a good one, and undoubtedly increases the size of the field. Air dilatation employed with the $22 \mathrm{~F}$ or $24 \mathrm{~F}$ tube of Joly's urethroscope has been found of great service. Harrison ${ }^{84} \mathrm{em}-$ ploys a special cannula made to fit his aero-urethroscope.

For chronic cases where gonococci are difficult to demonstrate, Norris ${ }^{62}$ advocates the following procedure :On the day previous to the bacteriological examination the vaginal walls are painted with a 5 to Io per cent. solution of silver nitrate until a definite local reaction is

$$
284
$$




\section{VULVOVAGINITIS IN CHILDREN}

obtained. Twenty-fours hour later the child is put in an elevated position, and half an ounce of bichloride of mercury, I in 5,000 normal saline solution, is injected into the vagina with a rubber syringe, thus ballooning out the cavity. A glass rod is then introduced, and efforts are made to detach strips of mucus and adherent secretion. The solution is forced in and out with the syringe, collected and centrifugalised at high speed for twenty minutes. The deposit is examined for gonococci.

In spite of Norris's great experience, we are very strongly averse from advocating any method of investigation which entails or includes the pernicious practice of securing a provocative reaction by chemical irritation. An efficient and harmless provocative effect may be produced by the administration of a moderately large dose of specific vaccine.

\section{Prognosis}

Although the course of the disease is characteristically a tedious one, cure can be guaranteed in the majority of cases. The disease seldom, if ever, survives the advent of puberty. Untreated cases in which the disease has persisted for years have been shown to go on to spontaneous recovery as puberty approaches. Many investigators insist that there is no reason to believe that the disease ever persists into adult life.

There is, however, a small percentage of cases which develop into true carriers. These unfortunate cases show no evidence of disease, no inflammation, no symptoms, no discharge. Yet they harbour the gonococcus, as far as we know, indefinitely. The ultimate prognosis of these cases is not known.

Ultimate anatomical damage is at least a definite possibility which must be considered in calculating the future of the patient.

In short, if we are guilty of unwarranted optimism in hoping for a speedy cure, we are at least justified in forecasting an eventual recovery. Relapse is characteristic, but subsequent resolution occurs in all but a very few cases. Complications are exceedingly rare, even if the risk of their occurrence is always present. Vaccine therapy is so potent a weapon, however, that their incidence is practically negligible. 


\section{BRITISH JOURNAL OF VENEREAL DISEASES}

\section{REFERENCES}

(I) Suchard. Rev. de la Suisse Romande, vii., 675.

(2) Atrinson. Amer. Jour. Med. Sci., I878, lxxv., 444.

(3) Potт. Jahrb.f. Kinderheilk., I883, xix.

(4) Skutsch. Inaug. Didd., Jena, I891.

(5) Koplik. Jour. Cut. and Gen.-urin. Dis., I893, ii.

(6) De Minine. Jour. de Méd. de Paris, June 8th, I895.

(7) Robertson, D. London Obst. Trans., I899, xiv.

(8) Romniceanu and Robin. Wien. Med. Presse, Igor, xlii., I97o.

(9) Kimball. Med. Rec., I903, lxiv., 76I.

(I0) VeIl and Bayon. Semaine méd., I904.

(II) Welt-Kakels. Baumgartens Jahrb., I904, 23 I.

(12) BAER. Jour. Inf. Dis., I904, i., 3I3.

(13) Holt. New York and Phil. Med. Jour., March I8th, I905.

(I4) Cotton. Arch.f. Pediat., I905, xxii., Ioo.

(I5) Plomley. Austral. Med. Gaz., I906, 455.

(I6) Hurdon. Kelly and Noble, Gyn. and Abd. Surg., I907, i., 8II.

(I7) Pollack. Amer. Jour. Derm. and Gen.-urin. Dis., I909, 289.

(I8) Morrow and Bridgman. Jour. Amer. Med. Assn., I9I2, lviii., I564.

(I9) Watson, D. "Gonorrhœa and its Complications," London, I9I $4,285$.

(20) Norris, C. C. “ Gonorrhœa in Women," I9I3, 376.

(2I) LEES, D. " Thomson's Gonorrhœa," I923, 473.

(22) TAussig, F. J. Amer. Jour. Med. Sci., I9I4, cxlviii., 480.

(23) Seippel. Illus. Med. Jour., I9I2, 50.

(24) Morton, H. H. " Genitourinary Diseases and Syphilis," I9I9, 240.

(25) Lancet, London, I922, ii., 744.

(26) RACHFORD. Am. Jour. Med. Sci., I9I7, cliii., 207.

(27) Epstein. Arch.f. Derm. u. Syph., I89I, xxiii., 3.

(28) Woods. Am. Jour. Med. Sci., I903, 3II.

(29) Hamilton, A. Jour. Inf. Dis., I908, v., r33.

(30) Stein. Surg. Gyn. and Obst., I923, xxxvi., 43.

(3I) Bendig. Münch. med. Woch., I909.

(32) Abt. Discussion, Venereal Disease Institute, March I5th, I922.

(33) Churchill and Soper. Jour. Am. Med. Assn., I908, i., 744.

(34) DukELSKI. Jahrb.f. Kinderheilk., I904, lix., 397.

(35) Spaulding. Amer. Jour. Dis. Child., I9r3, v., 248.

(36) Wollstein. Jour. Exp. Med., I907, ix., 588.

(37) Abraham, J. J. " Lectures on Gonorrhœa in Women and Children," London, I924, Io.

(38) Van Geison. Med. Rec., June IIth, I9Io.

(39) Irons and Nicoll. Jour. Inf. Dis., I9I5, xvi., 303.

(40) Pearce. Jour. Exp. Med., I9I5, xxi., 289.

(4I) BAYLY, W. "Venereal Disease," London, I924, I46.

(42) Norris and Mickelberg. Jour. Am. Assn., I92I, lxxvi., I64.

(43) Rubin. New York Med. Jour., I9I2, 339.

(44) Kolmer and Brown. Jour. Inf. Dis., I9I4, xv., 6.

(45) Smith, G. G. Amer. Jour. Dis. Child., I9I3.

(46) Cole and Lloyd. Jour. Path. and Bact., I9I7, xxi., 267.

(47) Anderson, R. A., Schultz, O. T., and Stein, I. F. Jour. Inf. Dis., I923, xxxii., 444. 


\section{VULVOVAGINITIS IN CHILDREN}

(48) Sмith, R. M. Post Graduate, I906, xxi., 26r.

(49) Fischer. "Diseases of Infancy and Childhood." 45 .

(50) Warden, C. Quoted by Stein, Surg. Gyn. Obst., I923, xxxvi.,

(5I) Report Roy. Soc. Med., Brit. Med. Jour., I925, i., 2 I4.

(52) Veillon and Halle. Arch. de méd. exper., I896, viii., 28I.

(53) SHERBER. Finger's Handb. der Geschlechtskrank., I9IO, i., I4I.

(54) Chapple. Lancet, I9I2, i., I685.

(55) Engering. Zeit.f. Hyg. u. Infektionskrank., September, I923, 3 I4.

(56) KidD and Simpson. "Common Infections of the Female Urethra and Cervix," London, I924, 97.

(57) Pontoppidan. Dermat. Woch., I9I5, lxi., I077.

(58) Bock. Zentralbl.f. Gynäk., October 9th, I920.

(59) Von Butzke. Deut. med. Woch., Igro, No. 32.

(6o) Perrin. Rev. Med. de la Souisse Romande, November 2oth, I9II.

(6i) Barnetr. Archiv. Pediatrics, I9r3, xxx., 650.

(62) Norris, C. C. Jour. Amer. Med. Assn., I9I5, 1xv., 327.

(63) Valentin. Deut. med. Woch., I92I, xlvii., 628.

(64) Hamilton, B. W. Jour. Amer. Med. Assn., igio, liv., i ig6.

(65) Doleris. Paris Méd., I9I2, May 4th.

(66) Rubin and Leopold. Amer. Jour. Dis. Child., I9I3, v., No. I.

(67) LuYs. "Gonorrhœa and its Complications," I9I7.

(68) BRUSCHKE. Therapie der Gegenwart, I902.

(69) Reith Fraser. Monograph on Gonorrhœa, I923, 46I ; South African Med. Rec., October 25th, I924.

(70) Findley, P. Western Med. Rev., I9I2, xvii., I86.

(7I) Wessels, D. H. South African Med. Rec., I923, xxi., 3 Io.

(72) Welt-Kakels. New York Med. Jour., October 8th, I904.

(73) Kaumheimer. Münch. med. Woch., May 3rd, I9Io.

(74) Dowd. Ann. Surg., February, I902.

(75) McDonagh. "Venereal Diseases," I920, 339.

(76) Martin, Thomas and Moorhead. "Genito-urinary Surgery," I Ith edition, 226.

(77) Jung. Centralbl.f. Gynäk., I904, No. 33.

(78) CARPenter. Brit. Jour. Dis. Child., I904, 437.

(79) Bidwell. Brit. Jour. Dis. Child., I904, 435.

(8o) Galvango. Arch. di Pat. e Clin. Infant., I904, ii., 73.

(8I) Variot and Sebilleau. Gaz. des Hôpitaux, I904, No. 28.

(82) Northrup. Arch. of Ped., I903, 9Io.

(83) SheAfF. Brit. Jour. Dis. Child., I9I7, xiv., 6r.

(84) Harrison. "Modern Diagnosis and Treatment of Syphilis, Chancroid and Gonorrhœa," London, I924, I59. Lancet, I923, ii., 336. 